\title{
A Criminological Profile Of White-Collar Crime
}

Tim V. Eaton, Miami University, USA

Sam Korach, Miami University, USA

\begin{abstract}
Using criminology as a foundation, this research explores the personality, psychology, and sociology of white-collar crime. While there has been much focus on various techniques (internal controls, prevention software, employee monitoring systems, etc.) to prevent fraud within companies and organizations, other important behavioral aspects have received less attention. The goal of this manuscript is to explore the literature from other disciplines to help better identify criminological personality profiles and incorporate different behavioral features such as personality characteristics, psychology, and sociology, with application to actual cases of white-collar fraud. Examining theory from other disciplines and merging it with the technical aspects of accounting and fraud prevention allows for a greater understanding of the motivations and processes behind these crimes and, hopefully, allowing for better prevention in the future.
\end{abstract}

Keywords: White-Collar Crime; Fraud; Psychology; Sociology; Personality; Criminology; Criminal Profiling

\section{INTRODUCTION}

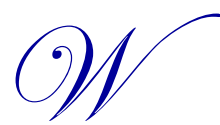

hile elements of white-collar crime can be traced back to the $17^{\text {th }}$ and $18^{\text {th }}$ century, the foundational study and advent of white-collar crime research has come to prominence in the past 50 years. The American sociologist Edwin Sutherland coined the phrase "white-collar crime" to define illegal acts committed both by individuals and organizations of higher statuses while performing in a legitimate occupation. (Barkan, 2012) Since Sutherland's presidential Address to the American Sociological Society in 1939, scholars have debated its precise definition and whether it is a definable concept at all. The contributions of different sociological critiques to the definition and debate was the focus of Gilbert Geis' work for nearly thirty years. At the end of his career, Geis (1991) concurred with criminologist John Braithwaite that the most applicable definition is still Sutherlands. While weaknesses and criticisms have been raised, most still believe that Sutherland's definition holds true. This study examines these white-collar crime topics in a manner consistent with Sutherland's attitude in his presidential address.

From a public lens, white-collar crime is a central reason why approval and trust of America's businesses have been eroded over the past three decades. In this span, Gallup polls of the American population have shown a downward, and then stagnant, trend of trusting corporate executives. A poll conducted in 2012 indicated only 18 percent believe that corporate executives have high levels of ethical conduct and honesty. (Gallup, 2012) Recent news reports show that the world of business has been inundated by unethical decision-making; searching Wall Street Journal articles with the keyword "fraud" yields over 3,300 articles in 2014 alone. Likewise, individualistic frauds continue to plague the world as Ponzi schemes, occupational fraud, insurance brokerage scams, and different types of property fraud deceive everyone from small business owners, to clergymen, to those who entrust the management of their retirement savings to friends. Unfortunately, these problems are not diminishing.

The Association of Certified Fraud Examiners' Report to the Nations (2014) arrived at some significant conclusions, including estimating that organizational loss due to fraud was approximately 5 percent of revenues, which totals about $\$ 3.7$ trillion for all businesses worldwide. The losses plaguing companies and individuals can range from a small amount of stolen merchandise to complex, million-dollar transactions. Nearly half of these organizations subject to fraud never fully recover any of the losses. As Ramamoorti (2009) indicates, there are self-identified weaknesses behind the methodologies used by the ACFE; however, the Report to the Nations does tell us quite a bit 
about the offenders and the offenses. For example, a majority of white-collar criminals are first-time offenders. Specifically with occupational fraud, approximately 87 percent had never been charged or convicted of a fraudrelated offense. (ACFE, 2014) In addition, this report can tell us information about who and how these crimes were committed. A majority of perpetrators are males in their mid-40s to mid-50s, and a significant number have college degrees. These statistics and estimates, which are consistent with the 2012 and 2010 reports, present corporate citizens and law enforcement alike with the remaining and unwavering challenge of identifying white-collar criminals.

\section{Criminal Profiling}

With white-collar crime being so widespread, it is important that organizations become aware of the criminological and behavioral elements that can be present in offenders' actions. One way to do this is to construct a criminal profile based on evidence that typically fits these crimes. Modern criminologists and law enforcement use criminal profiling to describe an investigative method that uses behaviors and psychological analysis to generate predictions about the characteristics of the most likely suspects of a crime. (Kocsis, 2007) While some debate its effectiveness, offender profiling has been successfully used in police practices for over a century. The term "profiling" was coined with the development of the FBI's Behavioral Analysis Unit in 1974 but has roots back to the late part of the $19^{\text {th }}$ century. The unit originally had applied it to serial homicide, but has since expanded its application to rape, arson, burglary, and terrorism. The disciplines that criminal profiling has utilized has since expanded from its original focus on psychology to the study of social networks, social processes, psychodynamics, and personality. (Canter, 2004)

Research into this style of investigation is in its embryonic stages, and as the field becomes increasingly popular, more studies will certainly surface. Approximately ten years ago, a survey was sent out to police departments across the country, which revealed that about 63 percent of the departments found the technique considerably useful in their investigations. Of the 37 percent that deemed it not useful, the main issues of concern were the lack of research and education to execute them. (Tragger, 2001) Since then, research into producing profiles has been augmented, and professions such as "criminal profiler" and "behavioral analyst" have become increasingly common within law enforcement circles, as well as within popular culture. While elements such as psychological processes, sociological environments, personality traits, and individual characteristics will be relevant in profiling white-collar crime, factors such as victimology and crime scene analysis are not relevant due to the nature of the crime.

\section{Integrating Criminal Profiling within the Fraud Meta Model}

The work of Dorminey et al. (2012) suggests the creation of an overarching meta model of white-collar crime by looking beyond the simple fraud triangle and interconnecting it with various other elements of the crime. Dorminey asserts that the Fraud Triangle alone may not be enough to capture the behavioral antecedents of white-collar crime. Rather, different individual characteristics and personality traits go into the overall human behavioral analysis. It is that dotted box in Dorminey's model that we believe fits the criminologist definition of a criminal profile. We will explain throughout the paper how the engagement of the previously listed disciplines will help construct a guide for what a white-collar crime offender profile may look like. 
Figure 1. Dorminey's (2012) Meta Model of White-collar Crime Initial Meta-Model of White-Collar Crime

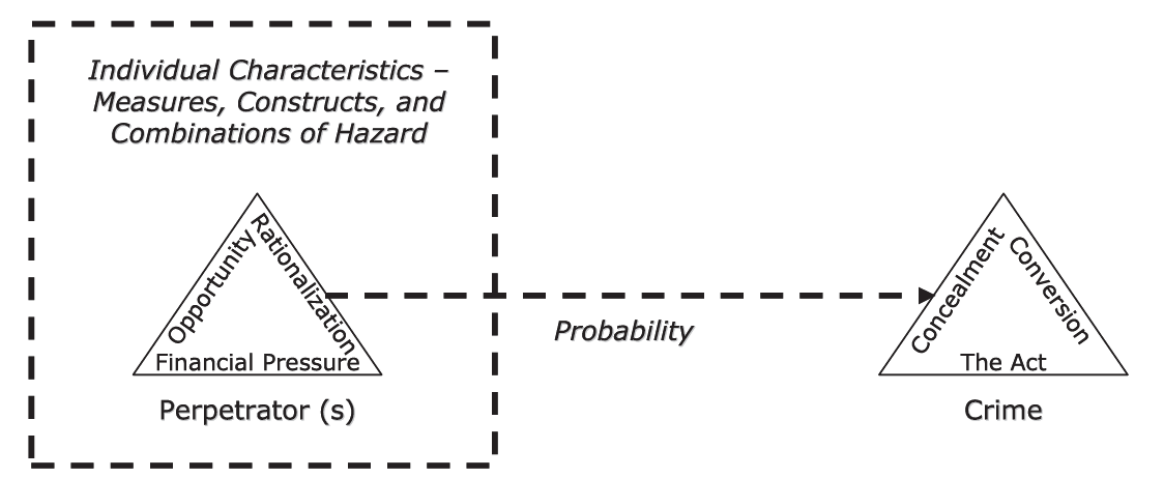

Regardless of the debates on the effectiveness of criminal profiling, knowing the personalities of past offenders, the psychological processes behind many white-collar crimes, and the type of cultures that inhibit white-collar crime can be extremely useful for not only fraud fighters, but also for the average employee. Profiling cannot explicitly identify the criminal as would a strand of DNA but, rather, acts as a guide to connect patterns of behavior to characteristics that would describe the offender. As Davis (1999) indicates, profiling is not intended to take the place of investigative work. However, when partnered with conventional investigative and forensic approaches, these profiles can add tremendous value. Our review of past cases, experiments, and testimonies sheds light on certain patterns that make up a general profile of a white-collar crime offender. Using criminological theory as a foundation, this research explores the personality, psychology, and sociology of white-collar crime and integrates these factors into an overarching profile.

\section{CHARACTER TRAITS}

Many profiles highlight certain character and personality traits of the unknown offenders. Although it is impossible to encapsulate all traits of all white-collar offenders, this section highlights a personality profile that has been validated in studies of past offenders. The limited listing of dispositions will promote the creation of a personality profile of these offenders, and by extension, a criminal profile. Research has shown that there may be many other traits that correlate with white-collar criminals; however, the succeeding four have been most apparent in the cases that have been most prominent in American business. These four traits are authority, cultural hedonism, narcissistic personality tendencies, and low self-control.

\section{Authority}

The first trait is an appreciation of and confidence in one's authority. Aguilera and Valdera (2008) assert that authority is a major part of corporate fraud and classify many business corruption cases as a classic use of power for personal or company gain. This trait is most apparent in executives who commit major corporate crimes, but can also be seen in some forms of smaller occupational crime. Most frauds are actually committed by employees, but in terms of length and magnitude, those in positions of power have an adverse effect that is nearly 8 times greater than that of a normal employee. (ACFE, 2014) Authority certainly is not a red flag on its own, as many leaders with authority have integrity and do not engage in criminal activity. A strong belief and confidence in one's authority and the availability of power held by corporate executives presents more of a problematic situation to fraud fighters. As Aguilera and Valdera (2008) indicate, while the way that white-collar criminals possess and obtain authority may differ, the result can often be the same and lead to some damaging conclusions.

German philosopher Max Weber was the first to study this concept from a sociological perspective, but he applied the term more so to political and economic resource domination. Regardless, Weber supplied the rest of the world with a definition that had multiple facets. Weber claimed that the three types of authority are legal, traditional, and charismatic. (Adair-Toteff, 2005) As far as white-collar crime is concerned, the legal classification really does not add significant value to the profile. Legal authority is normally tied to governmental or bureaucratic positions where power is obtained through voting, government constitutions and charters. 
Traditional authority, on the other hand, is derived when the right to rule is passed down through some intimate connection through the years. The significance of this authority is the process in which generations foster patterns of behavior and create tradition. In more ancient times, this could be seen in a line of pharaohs or kings that rule empires or dynasties for centuries. In business, it is more associated with family-owned businesses or private companies. However, it can also be seen in public companies where leaders are inherently trusted or promoted to positions regardless of technical ability or charisma. Typically, the employees below them offer little resistance to what has been established as the status quo.

According to Aguilera and Valdera (2008), the Rigas family is a prime example of overconfidence in authority. The Greek family had very significant control over Adelphia Communications Corporation and used their authority to create the norms and traditions that would lead to their eventual fall. Although they contested any intentional wrongdoings, some would suggest that the investigations into their Chapter 11 bankruptcy revealed that shareholder money and newly issued debt were being used to fund family purchases such as golf club memberships, parties, and a National Hockey League team. (Leonard, 2002) One could easily argue that traditional authority and a lack of board independence were facilitating factors in these actions, as it appears that the leaders of the company believed these actions would go unnoticed. Adelphia highlights a case in which traditional authority both limited implementation of controls and enabled the type of fraud that was committed.

The other type of authority is charismatic authority. Charismatic authority is Weber's way of explaining the acquisition of authority without a traditional or legal connection (Adair-Toteff, 2005). While legal and traditional authority stems from rationality, stability, and continuance, charismatic authority stems from innovation and personality. This type of authority is seen in many of the rags-to-riches stories that exist in corporate America. This does not suggest that charismatic leadership is a bad thing, because certainly there are charismatic leaders who do great things for companies, governments, sports teams, and others. What this does imply, however, is that too much confidence in authority and one's own personal successes can be dangerous and deplete or even eradicate a business's control environment.

Aguila and Valdera (2008) used the example of Enron's Jeff Skilling. Despite humble beginnings, Skilling became recognized as an increasingly notorious leader who has suffered heavily for his crimes. Skilling has been described as extremely charismatic. This creates an interesting inflection point, as many CEOs are thought to be charismatic. Where we believe the line should be drawn is when there is a presence of other positively associated traits (such as cultural hedonism, tendencies of narcissistic personality disorder, and low self-control) and/or sociological factors that facilitate an inefficient control environment.

\section{Cultural Hedonism}

The following three traits were all noted in a 2006 construct validity study by Blickle et al. of criminals and nonoffenders. The goal of the study was to detect where personality deviances existed between the two groups. Cultural hedonism, narcissistic personality disorder, and low self-control were statistically shown to be a correlate of offenders. The study was conducted using male prison inmates convicted of high-level white-collar crimes as well as high-level managers who had not committed white-collar crimes. The first validated hypothesis sought to confirm that white-collar criminals have a level of cultural hedonism. Even on a non-criminal level, one study has confirmed that high-level managers who are highly materialistic are less likely to contribute from a corporate social responsibility standpoint. (Tandon, 2011)

Hedonism, as a major trait, can be attributed to the material culture that many business people live in and the lifestyles that those aspiring in business want to achieve. Cultural hedonism within the United States stems from indulgence and the pursuit of accumulated wealth. Many people who enter professions of any rank typically do so to support a living and have an ultimate goal of wealth accumulation. However, a differentiating factor between ethical professionals and white-collar offenders can be the amount of stress placed on the level of hedonism. Coleman (1987) implies that even the competitive nature of business implies a sense of hedonistic qualities that may carry over into offenders' personal traits and motivations. According to the Report to the Nations (2014), approximately $43.8 \%$ of perpetrators were living beyond their means at the time of the fraud, and $37 \%$ were experiencing financial difficulties. From what previous research has indicated, it seems as if the roots of this stress can essentially be broken down into two sources: performance-based compensation and hedonistic attitudes. 
One stressor for white collar criminals is the hedonism of the executives and the drive to continually increase executive pay. In fact, the rising demands of corporate executives has dramatically increased executive compensation roughly 256 percent over the course of the last two decades and struck a 16-percent pay increase over the past year (the average American worker received a 3 percent increase). (Forbes, 2012) In addition, high-level corporate white-collar crime can be triggered by the speculation of material gains or the fears of financial losses. This motivation can be connected with performance-based compensation. Pay-for-performance analysis and evaluations have been implemented by approximately 70 percent of companies. (Meridian Compensation Partners, 2013) With both of these stressors in place, one can infer that this higher level of hedonism presently exists with upper level executives and is even embedded into their compensation. A strong focus on cultural hedonism combined with opportune circumstances can contribute as motivation and enticement towards unethical conduct.

\section{Narcissistic Personality Tendencies}

The second hypothesis tested in the 2006 Blickle et al. study was whether the presence of diagnostic features of Narcissistic Personality Disorder (NPD) would lead to a higher probability of committing a white-collar crime. The American Psychiatric Press Review of Psychiatry identifies the conception of NPD to include traits such as demands and illusions of grandeur, being an exhibitionist, a desperate need for uncritical admiration, entitlement, a lack of sustained commitment to others, and a deficient ability to empathize with others. (Cooper \& Ronningham, 1992) Various examples will confirm that these parts of the definition fit the personalities of some of the most formidable white-collar criminals. Recently, the existence of this disorder, versus whether these tendencies exist within all humans, has been widely debated. Multiple studies actually suggest that it is more appropriate to classify NPD as trait narcissism on a dimensional scale rather than an absolute label. (Foster \& Campbell, 2007, Foster, Campbell \& Twenge, 2003) It is for this reason that we will not recognize NPD, but rather discuss the tendencies that describe the former disorder. Using aforementioned definition, we explore three main qualities that seem to reoccur in whitecollar crime cases.

In regards to grandiosity, many white-collar criminals who perpetrated large-scale crimes can live lavish lifestyles resembling that of Shawn Merriman. As for the need for admiration, many executives at Enron had the fatal flaws of always wanting to please Jeff Skilling. For a lack of empathy, an example would be the actions of Kevin Dunn, a man who took nearly $\$ 250,000$ from a 9/11 widow's compensation for the loss of her husband on one of the worst days in American history. (Marzulli, 2009) When diagnosed, NPD is only present in about 1 percent of the population, but some psychologists assert that trait narcissism exists in most of us on a dimensional level. Although these traits are existent in most, the expression of signs/tendencies of the disorder seem to be correlated with whitecollar crime, as Blickle et al. (2006) suggests.

\section{Low Self-Control}

The final prominent trait of white-collar criminals is an exhibition of low self-control. The Blickle (2006) study also concluded that the lower the behavioral self-control of a person, the more likely they were associated with committing a white-collar crime. Very frequently, one of organizations' most sizable human resource risks is placing people in positions of trust, who then abuse their positions of authority. Unfortunately, when a sufficient amount of pressure and opportunity is available, a trait like low self-control can facilitate white-collar crime. Actions exhibiting low self-control tend to all involve immediate gratification; they represent relatively uncomplicated means to that gratification; they are somewhat risky and exciting; they provide direct benefits to the perpetrator; and finally, there is a belief that victims will be harmed minimally. (Moberg, 1997)

The character trait of low self-control is rooted in criminological theory, as is its connection with white-collar crime. Developed by Michael Gottfredson and Travis Hirshi (1990), self-control theory was presented as a revised social control theory in their book "General Theory of Crime." The basis for their argument is that self-control, or a lack thereof, stems from the way in which a criminal perceives the consequences to their actions. They note that three different types of criminals are all prone to lack a calculation of consequence and, therefore, warrant the labeling of a low level of self-control. The impulsive criminals typically do not think much about negative consequences and make rash decisions. The insensitive criminals really don't care much or consider the potentially painful impact their actions can have on others. Finally, the less intelligent criminals have less to consider and do not have the foresight. 
(Gottfredson \& Hirschi, 1990) While all of these points seem valid, white-collar crimes seem to err more towards the impulsive and insensitive crimes rather than the lack of intelligence. In fact, Blickle et al. insinuates that intelligence and an overall social conscientiousness may even allow white-collar criminals to enter the positions in which they commit crimes One study tested the global nature of the lack of self-control in connection with crime. Vazsonyi et. al.'s (2001) comparison of self-control and deviance subscales across four nations (one being the United States) shows that it is a consistent trend in not only different types of crime, but also different areas of the world. A speech that Andy Fastow gave to the ACFE, exemplifies this. Fastow self-admitted a lack of self-control when it came to the financial structures that he put in place to make Enron appear to be in better financial condition than they were. "Did I know it was wrong? Absolutely. I knew I was doing something wrong, but at the time I didn't know it was illegal. Once you start doing these types of transactions, when do you stop? I just didn't stop." (Pavlo, 2013).

To summarize this section on character traits, four key personality traits can contribute to the overarching profile of white-collar criminals:

(1) Overconfidence and over-appreciation for self-authority

(2) Cultural hedonism

(3) Signs/symptoms of Narcissistic Personality Disorder (Trait Narcissism)

(4) Lack of self-control

Each of these can be potential red flags when looking to promote or hire potential candidates. However, in order to make more sound judgments on what makes up this criminal profile, one has to understand the psychological and sociological factors that contribute to white-collar crime as well.

\section{PSYCHOLOGY \& SOCIOLOGY}

To fully understand how and why a white-collar criminal operates, one must obtain a brief understanding of behavioral science. The basic foundation of a behavioral science approach is that white-collar crime is similar to all crimes in a structural sense. All crimes contain a stock of motivated and pressured offenders, vulnerable targets, and the lack of capable or willing guardians that would prevent the act.

The model that serves as a foundation for the psychological process in this section is what the ACFE calls a "Fraud Triangle." The Fraud Triangle concept was introduced to corporations through the Statement on Auditing Standard No. 99 in reaction to the major downfalls of Tyco, WorldCom, Arthur Andersen, and Enron. This structure is a formation of opportunity, pressure, and rationalization. (SAS No. 99, Consideration of Fraud in a Financial Statement Audit) Contrary to popular thought, the Fraud Triangle is not simply a psychological process, but has deep roots in sociology as well. Instead of simply rehashing the fraud triangle, our goal is to integrate some of the personality correlates with the psychological and sociological elements of the fraud triangle to enrich the behavioral portion of Dorminey's (2012) meta-model of fraud. Integration of personality into these disciplines rounds out the relevant components of what a white-collar criminal profile would look like.

\section{Opportunity}

The first portion of the triangle is opportunity. Opportunity is essentially a situation or combination of circumstances that create a pathway for fraud to occur. Some of these opportunities can be embedded in internal controls, corporate culture, and effective management. (Ramos 2003) For the sake of white-collar crime, the style of opportunity we are highlighting deals with the situational factors of the industry itself, the corporate environment that workers are in, and the current state of the organization. Opportunity is situational, but it also has sociological influences. These influences also tend to connect and tie in with some of the character traits identified previously.

A first opportunity is created through an industry's culture, norms, and expectations. Trends have shown that firms in certain industries are, indeed, correlated with being more likely to commit unethical practices and contain similar levels of criminal activity. (Gray, 1995) Likewise, a previous study has shown that industries follow the norms and trends of illegal activity, as these rates and changes do vary from industry to industry and even with factors such as 
profitability. (Simpson 1986) In addition to culture and norms, expectations for an industry, especially for those involving the use of new technology, can become irrational and unreachable for owners of business processes. Expectations to reach the investor and analyst predictions create an opportunity to commit unethical practices in pursuit of the bottom line expectations of the company or business unit. (Ramamoorti, 2008) A second opportunity is created through a firm's structure and culture. One trait recognized in the correlation between environment and illegal activity is the size of the company. One explanation is that increased size creates complexity in an organization that interferes with communication and coordination. Another explanation would be that size creates more freedom and decentralization and, therefore, provides an easier setting for white-collar crime than smaller, more closely monitored firms. (Dalton \& Kesner, 1998) Ramamoorti's (2009) ABCs help to explain some of the sociological perspectives on how culture may facilitate crime. The theory describes the differences between bad Apples (individuals), bad Bushels (sub groups) and bad Crops (overall group). Within opportunity, a firm's culture can facilitate the creation of bad bushels or bad crops that influence unethical or even criminal behavior on an individual level.

Not specific to any organization, but pertaining to the business world as a whole, is the motivation of profits. As discussed earlier, cultural hedonism is the term used for the high stress on materialistic value. This view of business creates a culture where the quest for profits has the potential to drive businesspeople into acts that can be harmful to society, especially in competitive industries. Additionally, opportunity is enlarged by some perpetrators being in positions of authority and having overconfidence in that authority. A predominant focus on the pursuit of profits and confidence in one's authority facilitates opportunities in which white-collar criminals can rationalize that their acts are for a greater purpose. (Lehman \& Okcabol, 2005)

BP exemplified one of these competitive, profit-based cultures. Following congressional committee hearings, it was revealed that BP neglected audit and maintenance work in order to cut costs. Even following this hearing, it continued its course, which ultimately contributed to the Gulf oil spill in 2010. (Herscher, 2010) In addition, Arthur Andersen became a place where more stress was put on salesmanship and profit than on ability and quality of work.Despite the cultural flaws at BP and Arthur Andersen, perhaps none was worse than the "Bad Crop" at Enron. The firm has since become synonymous with fostering an environment that is motivated strictly by profits, employeesbeing targeted for their proficiency to excel in a culture that was built on a "Darwinian" philosophy of rewarding profit makers and condemning those who could not get the deals done. This culture, combined with the knowledge of complicated fraud tactics, created the opportunity to commit one of the gravest white-collar crimes that has ever been studied.

Opportunity is not simply organizational or corporate, however. Many individualistic crimes get tied up in the same creation of opportunity. None may provide a better example than the case of ex-MetLife broker Kevin Dunn. Dunn was convicted for stealing approximately $\$ 250,000$ from a vulnerable 9/11 widow, Jamie Amoroso, to remodel his own house and buy a condo in Florida. Judge Leo Glasser condemned Dunn by scolding his inability to do the right thing when the opportunity to take the money presented itself to him. He noted that Dunn had an opportunity to do a good or bad thing. (Marzulli, 2009) Dunn certainly displayed authority and hedonistic traits that were apparent in his creating, facilitating, and capitalizing on opportunity.

With the structure of most white-collar crimes, there is a viable opportunity. Whether it is fraud, Ponzi scheme, insider trading, or kickbacks, there are always opportunities. However, opportunities alone do not cause crime, even if several traits that would fit within our profile are present. Discovering the origins of why they are acted upon comes through studying a criminal's motives and justifications. Regardless, it is important to recognize the cultural and personal circumstances that can position a potential offender in the right place and time to commit the crime.

\section{Motivation}

Whether crime is organizational or individualistic, the opportunity and motivation connections in the Fraud Triangle are heavily rooted in criminological psychology and social theory. Opportunity creates a situation in which general deterrence theory, rational choice theory, and general strain theory can take their course in the form of motivation. Each of these theories deals with the decision of whether or not to commit a crime based on the situation that is presented. While none of these theories is bullet-proof, each offers an explanation into why all crime, not just whitecollar crime, is committed. 


\section{General Deterrence Theory}

The first theory is general deterrence theory. This theory addresses the prevention of the illegal act more than it does the criminal act itself. This neoclassical theory is based on what happens when the decision maker believes that the risks outweigh the potential rewards, making it the converse of rational choice theory. While this may seem empirically difficult to prove, there have been several anecdotal publications and empirical studies that have continued to support this theory. (Quackenbush, 2010; Higgin, 2005; Thornton 2005) Within this theory, there are two different types of deterrence: general and specific (also referred to as immediate). With white-collar crime, only general deterrence typically applies. This type of deterrence takes effect when potential wrongdoers decide not to break the law because of the preemptive fear of punishment regardless of whether or not they were contemplating the crime. (Morgan, 1983)

While this may be more of a "demotivational" theory, it still fits under the motivational aspect of the fraud triangle as it applies to the act. The deterrence in white-collar crime most blatantly comes from jail time, but it may also include public humiliation, loss of respect, and even the collapse of an entire organization, as was seen in the case of ImClone. Since being released from prison, Sam Waksal has considered himself an important form of deterrence for people who face ethical dilemmas while working. (Leung, 2009)

\section{Rational Choice Theory}

The second theory involved in this point of the triangle is rational choice theory. Another neoclassical theory, rational choice theory asserts that the will to act after balancing the potential risks and rewards is how crime occurs. Contrary to general deterrence theory, rational choice is more about the motivations that convince the potential criminal to commit the crime. Often accredited to economist Gary Becker, rational choice theory makes committing crime a decision about utility of the circumstances. Barkan (2012) reveals several factors in his discussion of rational choice theory, which includes (1) a person's opportunities to earn legitimate money, (2) how much of that legitimate money is available, (3) the amount of money they can gain from committing crime, (4) the likelihood of being caught, and (5) once caught, the probability of being punished.

This theory, however, is just as individual as it is social, meaning that factors in corporate culture and situations can be just as influential motivators as the need for personal gain. (Hechter \& Kanazawa, 1997) Ramamoorti's (2009) ABCs would apply consistently with this assertion, as motivations could be seen in all three categories. With the nature of this motivational theory being economical, most research on the theory has been done with economic gain in mind. Likewise, with a business mindset in place, most corporate crimes consist of an internal cost-benefit analysis that either persuades or dissuades people in moments of opportunity. (Paternoster \& Sally 1993)

This theory applies universally; however, most research has been done in Europe, as it has become a sociological staple for their society. Research has been executed in the form of differentiating test strategies, experimental studies, and bridge assumptions. (Kroneberg \& Kalter, 2012) While seemingly simple, rational choice theory is part of daily life as well as criminal action.

\section{General Strain Theory}

The final motivational sociological theory is general strain theory. Strain theory, as Zahra et al. (2005) claims, is one that "proposes that societal norms affect individuals" aspirations for things like material goods and other indicators of success. Individuals who are unable to achieve their aspirations by conventional means experience strain and may seek to relieve this strain by using deviant means to achieve their desired ends." (Zahra et. al, 2005, p. 813) While this explanation really merges strain and differential theories, the message is quite clear. Some companies may find themselves in a strong push for profits and therefore may overcharge or cut costs because, conventionally, they cannot achieve those targets. Likewise, individuals may have to use unconventional or illegal means in order to achieve a certain status or amount of wealth.

Two major categories for the type of strains exist. Monetary and status-related strains pertain to white-collar workers more so than family or internal struggles. Economic strains can be both on an individualistic or corporate level, with 
many convicted offenders claiming that they either were motivated by the pursuit of profits or had the social pressure to prevent losses. (Agnew, 2009) Likewise, with status as a motivation, we return to the personality trait of cultural hedonism. Whether it be someone of the lower or upper class, American attitudes are often characterized by trying to reach economic goals beyond their reach. (Durkheim, 1951) As we see the triangle being integrated with the identified character traits, we can begin to see where self-control can emerge between the notions of opportunity and motivation to cause an action.

\section{Rationalization}

The final stage to the psychology of fraud and the "Fraud Triangle" is justification of the act. These justifications come in many different forms before and after the crime has occurred. Justifications are ways in which individuals who engaged in unethical, corrupt, and illegal activities can legitimize their behavior. When crimes are committed, there is a cognitive dissonance between the accepted moral standards of the time and the wrongdoing. To deal with this, many white-collar criminals try to close that gap through different kinds of justification. (Aguilera \& Vaadera, 2008) Justifications may occur before the act, as discussed previously by Becker's rational choice theory, or they may be retrospective, as explained by Sykes and Matza's neutralization and drift theory. This theory asserts that white-collar criminals use techniques of neutralization to void any feelings of guilt or justify their actions. Overall, sociologists debate on just how many techniques exist; however, for our purposes we will use four major and three minor techniques.

Heath's (2008) perspective on business decisions and moral motivations delves into the list of neutralizations that are used to bridge the gap between what is legal or ethical and what is done. The first technique is the denial of responsibility. In many organizational crimes, it is not solely one person acting out of line, but an expanded network of people who ordered the action, to the people who carried it out, to the people who tried to cover it up, etc. With the hierarchal structure of most business, the blame is averted to the superiors by the inferiors, and vice versa.

The second is a denial of injury. This aspect is very specific to white-collar crime, in particular. Whereas in an assault, rape, or robbery, an individual comes face-to-face with a victim, white-collar crime is seen as a faceless crime where the perpetrator never actually interacts, sees, or meets the people who are affected by their poor decision making.

The third justification technique is the denial of the victim. This technique asserts that the victim is not actually hurt, because they owe what was taken from them. For example, when an employee at a bagel shop makes himself a sandwich without paying for it, or when a financial advisor creates fake charges to go directly into his personal account, both could be self-justified that they should be compensated for more than what they are getting. In addition to deserving more compensation, they feel that they earned what they took.

The next technique is the condemnation of the condemners. It is at this point that the offender will blame the system, the prosecution, the judge, the press, or anyone who condemns them for their actions. Oftentimes executives and managers argue whether or not the law that they are charged with breaking is legitimate, or they attack the motives and methods of those who try to enforce and indict them. When the intensity of questioning increased in the Enron trial and questions of the departed Cliff Baxter came up, Jeff Skilling turned it right back on the press and on those who were prosecuting. According to Skilling, it was not the proverbial writing on the wall or the financial distress that led to the suicide of one of his friends, but those who were investigating the storyline. "They are calling us child molesters.' He says, 'That'll never wash off."' (U.S. House Committee on Energy and Commerce, 2002)

The three final justifications are considered minor because they do not typically strongly apply to white-collar crime as much as the previous four. The first of these three is appeal to higher authority, where the justification is that they abide by some greater set of laws or codes of conduct. An example would be a crime for the sake of religion or loyalty to another. The second is an "everyone else is doing it" type of mentality. An example of this would be a manufacturing company infringing on worker safety rights because the rest of the industry is doing so. And a final justification is a straightforward disregard for the regulation that is put in place. It is the attitude that businesses should not have to answer to government in a laissez-faire ideology and that they are capable of handling their own affairs. 
When we continue to think within the context of Dorminey's (2012) meta model, the main trait that is associated with rationalization is narcissistic personality tendencies. To recall, the components of this disorder are grandiosity, a need for admiration, and a lack of empathy. The rationalization process would fit in heavily with the contexts of lack of empathy. The interconnectivity of the psychological process (rationalization) and the character trait (narcissistic tendencies) goes well to serve the merging of the two within Dominey's model.

\section{SUMMATION OF THEORY/IMPLICATIONS}

These theories, studies, and experiments make the case that white-collar crime is a human act, and is therefore heavily filled with human elements. The various theories involving cultures, attitudes, and psychological processes show that these crimes are about more than just greed. They can be about pressure, ego, and even a lack of selfcontrol. Much as it is impossible to call every serial killer the same, it is also impossible to call every white-collar criminal the same. However, with many of the tendencies and modi operandi being similar, profiles can slowly become increasingly helpful to law enforcement and organizations in mitigating risks through hiring/recruitment, internal controls, etc.

Figures 2 and 3 show the elemental structure of each of these disciplines:

Figure 2. Personality Elements of the Criminological Profile of Fraud

\begin{tabular}{ll}
\hline & \multicolumn{1}{c}{ Personality Profile Elements } \\
\hline Authority & $\bullet$ Traditionally Acquired \\
& $\bullet$ Charismatically Acquired \\
\hline Cultural Hedonism & $\bullet$ Pursuit of Performance \\
& $\bullet$ Pay for Performance \\
& $\bullet$ Individual Greed \\
\hline Narcissistic Personality Disorder & $\bullet$ Grandiosity \\
& $\bullet$ Need for Admiration \\
& $\bullet$ Lack of Empathy \\
\hline Low Self-Control & $\bullet$ Gottfredson and Hirshi's Self Control Theory of Crime
\end{tabular}

Figure 3. Psychological \& Sociological Elements of a Criminological Profile of Fraud

\begin{tabular}{|c|c|}
\hline \multicolumn{2}{|r|}{ Pyschological And Sociological Profile Elements } \\
\hline Opportunity & $\begin{array}{l}\text { - Industry Culture } \\
\circ \quad \text { Culture, Norms, and Competition } \\
\circ \quad \text { Lack of Regulation/Defined Rules } \\
\text { - Corporate Culture } \\
\circ \quad \text { Size, Norms, and Expectations } \\
\text { - Individual Trust }\end{array}$ \\
\hline Motivation & $\begin{array}{l}\text { - General Deterrence Theory } \\
\circ \quad \text { Potential Risks Outweigh Rewards } \\
\text { - Rational Choice Theory } \\
\circ \quad \text { Potential Rewards Outweigh Risks } \\
\text { - General Strain Theory } \\
\circ \quad \text { Economic Strain } \\
\circ \quad \text { Individualistic Status Strain } \\
\end{array}$ \\
\hline Neutralization & $\begin{array}{l}\text { - Sykes and Matza Neutralization Theory } \\
\circ \text { Denial of Responsibility, Injury, and Victim } \\
\circ \quad \text { Condemnation of Condemners } \\
\circ \quad \text { Appeal to Higher Authority } \\
\circ \quad \text { "Everyone else is doing it" } \\
\end{array}$ \\
\hline
\end{tabular}

As discussed throughout this manuscript, within the contexts of personality, sociology, and psychology, some connections can allow the disciplines to work together. While the appreciation of and confidence in authority is a trait seen in individuals, it can also be a by-product of a corporate culture, and therefore, the opportunity point of the 
triangle. Cultural hedonism can be connected to corporate culture, with motivation using pay-for-performance programs facilitating avarice. Narcissistic personality traits can certainly coincide with neutralization, as lacking empathy would often include the denial of responsibility and committing a crime. Finally, low self-control, as outlined earlier, would certainly come into effect when opportunity and motivation meet to make a decision to commit a crime. The interrelation in these disciplines is shown in Figure 4 below:

Figure 4. Interrelation of Personality and Fraud Triangle Components

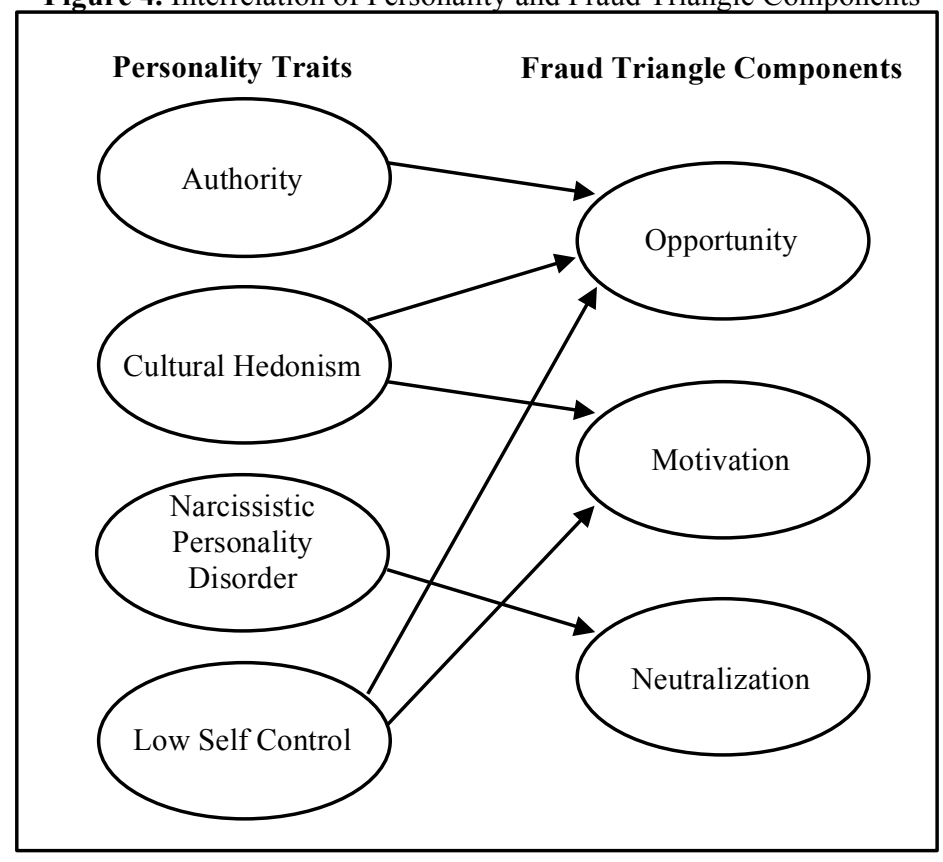

This information can aid fraud fighters in solving and preventing some of these crimes. White-collar crime, in itself, is the fusion of both criminology and business. Where the business professionals understand the technical actions of crime, the criminal sociologists and psychologists can understand its underlying causes. (Sutherland, 1940) The merging of these two disciplines can allow for a greater understanding of the internal processes behind these crimes. However, as mentioned before, these criminological profile assumptions are not absolute truths. Most profiles are not completely accurate, but rather can act as a helpful guide for detecting and solving crime. While a suspect may fit parts of the psychological and sociological profile, he would not necessarily fit all parts of the personality profile.

Some of these theories do present interesting possibilities on how to prevent crime. With regards to personality, it is extremely difficult to mitigate a person's own nature. However, there are different techniques to reducing the temptations that may come along with authority and cultural hedonism. From this research, companies may want to sway away from cultures created by the fear of an unchallenged authority. These instances were seen, as discussed previously, with Adelphia as well as in the "Career Limiting Moves" of Arthur Andersen. In regards to hedonism, it really is a trait that is socially constructed. The implications from this would be to reduce pay-for-performance programs for top-level CEOs and instead structure their pay more on the accomplishments of the collective. In other words, a team incentive program could be implemented rather than an individual one. Some of these programs would encourage collaboration rather than motivation purely for self. (Hoffman \& Rogelberg, 1998) This may mitigate the risks that come with a high cultural hedonism. While employers may not be able to aptly control for narcissistic personality traits, low self-control, as stated earlier, may come from a misunderstanding or lack of awareness of the consequences. A way to protect against this would be to have industry-wide education and training into how devastating these crimes can be not just to the companies or individuals, but to other stakeholders as well.

From a psychological and sociological standpoint, there are several implications that these theories can have on preventing and mitigating the risk of white-collar crime. General deterrence and rational choice theory will have similar implications on the communication of consequences and the need to show people with opportunity that the 
risks clearly outweigh the benefits. The insinuation from neutralization and drift theory shows us seven different justifications for crime. These justifications can allow investigators to speculate on what the perpetrator of a crime used to justify their actions. Overall, obtaining a psychological understanding of any perpetrator can allow investigators to develop ways of planning an investigation and coordinating an interrogation. (Tragger et. al., 2001) In the future, as fraud will likely continue, it is important to obtain knowledge from other disciplines and merge it with accounting techniques. Research into criminological profiling and the behavioral aspects of white-collar crime is in early stages of development; the goal of this manuscript is to help expand the field of knowledge by examining theory from other disciplines and merging it with white-collar crime analysis, allowing for a greater understanding of the motivations and internal processes behind these crimes.

\section{ACKNOWLEDGEMENTS}

This research was funded by a grant from EY.

\section{REFERENCES}

2002 U.S. House Committee on Energy and Commerce. Financial Collapse of Enron: Part 2. Library of Congress pg. 152 Adair-Toteff, C. (2005). Max Weber's Charisma. Journal Of Classical Sociology, 5.2, 189-204.

Agnew, R. et. al. (2009). General strain theory and white-collar crime. The criminology of white-collar crime. 35-60. New York, NY: Springer

Aguilera and Valdera. (2008). The Dark Side Of Authority: Antecedents, Mechanisms, and Outcomes Of Organizational Corruption. Journal Of Business Ethics, 77(4), 431-449

Association of Certified Fraud Examiners. (2014). ACFE report to the nations.

Barkan S. (2012). Neoclassical perspectives: Rational choice theory. Criminology: A Sociological Understanding,. Upper Saddle River, NJ: Prentice Hall, 119-222, 319-322

Blickle et. al. (2006). Some Personality Correlates Of Business White-Collar Crime. Applied Psychology: An International Review, 55(2), 225-228

Cohn, M. (2013). Former Enron CFO Andrew Fastow confronts the fraud examiners, Accounting Today. http://www.accountingtoday.com/news/Former-Enron-CFO-Andrew-Fastow-Meets-Fraud-Examiners-67263-1.html

Coleman, J. (1987). Competition and Cooperation. Ethics, 76-90.

Cooper, A., and Ronningstam, E.(1992). Narcissistic Personality Disorder. American Psychiatric Press Review of Psychiatry. 11.

Dalton D. and Kesner, I.F. (1998). On the Dynamics of Corporate Size and Illegal Activity: An Empirical Assessment. Journal of Business Ethics, 7.11, 861

Davis, J. A. (1999). Criminal Personality Profiling and Crime Scene Assessment A Contemporary Investigative Tool to Assist Law Enforcement Public Safety. Journal of Contemporary Criminal Justice, 15(3), 291-301.

Dorminey, J et. al. (2012). The Evolution of Fraud Theory. Issues In Accounting Education, 27(2), 555-579

Durkheim, Emile (1951 [1897]) Suicide: A Study in Sociology. Trans. J.A. Spaulding and G. Simpson. New York: The Free Press.

Ebbers defense closing argument: It's Sullivan's fault.(2005). Fox News. $<$ http://www.foxnews.com/story/200 5/03/04/ebbersdefense-closing-argument-it-sullivan-fault/>.

Foster, J.D. \& Campbell, W.K. (2007). Are there such things as "narcissists" in social psychology? A taxometric analysis of the Narcissistic Personality Inventory. Personality and Individual Differences, 43, 1321-1332.

Foster, J.D., Campbell, W.K., \& Twenge, J.M. (2003). Individual differences in narcissism: Inflated self views across the lifespan and around the world. Journal of Research in Personality, 37, 469-486.

Geis, G. (1991). White-Collar Crime-What Is It. Current Issues Crim. Just., 3, 9.

Gottfredson, M., and Hirshi, T. (1990). A general theory of crime. Stanford, CA: Stanford University Press 95-96.

Gray, D. et al. (1995) Top Management Team Characteristics And Corporate Illegal Activity. Academy Of Management Review, 20.1, 141-142

Heath, Joseph (2008):. "Business Ethics And Moral Motivation: A Criminological Perspective." Journal Of Business Ethics 83.4, 595-614

Hechter, M. and Kanazawa, S. (1997). Sociological Rational Choice Theory. Annual Review of Sociology, 23, 191-214

Herscher, P. (2010). From BP and Wall Street: Corporate culture impacts performance. HuffPost Business. $<$ http://www.huffingtonpost.com/penny-herscher/from-bp-and-wall-st-corpo_b_563211.html $>$.

Higgins, G. et al. (2005) An Application of Deterrence Theory to Software Piracy. Journal of Criminal Justice and Popular Culture, 12.3, 166-184.

Hirschi, T., and Gottfredson, M. (1987). Causes Of White-Collar Crime. Criminology, 25.4, 949-974

Hoffman, J. R. and Rogelberg, S.G. (1998). A guide to team incentive systems. Team Performance Management, 4.1, 23-32. 
Honesty/Ethics in professions. (2012) Gallup: 2.<http://www.gallup.com/poll/1654/honest y-ethics-professions.aspx Ibrahim, J. (2012).Allen Stanford: Descent from billionaire to inmate \#35017-183, CNBC www.cnbc.com/id/49276842

Kocsis, R. (2007) “Criminal Profiling: International Theory, Research, and Practice” New York, NY: Springer, 365-366

Kroneberg, C. and Kalter, F. (2012). Rational Choice Theory And Empirical Research: Methodological And Theoretical Contributions In Europe. Annual Review Of Sociology, 38,73-92

Lehman, C, R. and Okcabol, F. (2005). Accounting For Crime. Critical Perspectives On Accounting, 16.5, 613-639.

Leonard, D et.al. (2002). The Adelphia story. Fortune Magazine. pp. 4-5 $<$ http://money.cnn.com/magazines/fortune/fortune_archive/2002/08/12/327011/>

Leung, R. (2009). Sam Waksal: I was arrogant. CBS News. $<$ http://www.cbsnews.com/8301-18560_162-576328.html>.

Martino, J. (2012).The Mormon Madoff: How Shawn Merriman scammed millions. $C N B C$. $<$ http://www.cnbc.c om/id/47881681>.

Marzulli, J. (2009). Judge sentences 'heartless' ex-MetLife broker to 51 months in prison for 9/11 widow swindle. NY Daily News. <http://www.nydailynews.com/news/crime/judge-sentences-heartless-ex-metlife-broker-51-months-prison-9-11widow-swindle-article-1.421212>.

McLean, B. and Elkind, P. (2003). The smartest guys in the room: The amazing rise and scandalous fall of Enron New York, NY: Penguin Books Limited. 55-60, 114.

Meridian Compensation Partners LLC. (2013). 2013 Trends and developments in executive compensation. $<$ http://www.meridiancp.com/images/uploads/2013_Trends_and_Developments_in_Execu tive_Compensation.pdf $>$.

Moberg, D. J. (1997). On Employee Vice. Business Ethics Quarterly, 7.4, 41-60

Morgan, P.M. (1983). Deterrence: A conceptual analysis, New York, NY: Sage Publication

Paternoster, R., and Sally S. (1993). A rational choice theory of crime. Routine Activity and Criminal Choice, 37-46.

Pavlo, W. (2013). Former Enron CFO Andrew Fastow speaks at ACFE annual conference. Forbes Magazine. $<$ http://www.forbes.com/sites/walterpavlo/2013/06/26/fmr-enron-cfo-andrew-fastow-speaks-at-acfe-annualconference/>.

Quackenbush, S. L. (2010). General Deterrence And International Conflict: Testing Perfect Deterrence Theory. International Interaction, 36.1, 60-85.

Ramamoorti, S. (2008). The Psychology And Sociology Of Fraud: Integrating The Behavioral Sciences Component Into Fraud And Forensic Accounting Curricula. Issues In Accounting Education 23.4, 517-533.

Ramamoorti, S., Morrison, D., \& Koletar, J. W. (2009). Bringing Freud to Fraud: Understanding the state-of-mind of the C-level suite/white collar offender through "ABC" analysis. The Institute for Fraud Prevention, 1-35.

Ramos, M. (2003). Auditors' Responsibility for Fraud Detection. Journal of Accountancy. January-2003, 28-32. $<$ http://users.ipfw.edu/pollockk/SAS99Article.pdf>.

SAS No. 99, Consideration of Fraud in a Financial Statement Audit, Paragraph 05

Simpson, S. S. (1986). The Decomposition of Antitrust: Testing a Multi-Level Longitudinal, Model of Profit Squeeze. American Sociological Review, 51; 866-67

Stevens, G. et. al. (2012). Successful Psychopaths: Are They Unethical Decision-Makers And Why?. Journal Of Business Ethics, 105.2, 139-149.

Sutherland E. H. (1940). White-Collar Criminality. American Sociological Review , 5.1, 1-12

Tandon et. al. (2011). What Discriminates The Prospective Manager's Attitude Towards Corporate Social Responsibility? An Insight From Psychological Variables. IUP Journal Of Corporate Governance, 10.3, 52-70.

Thornton, D. et. al. (2005). General deterrence and corporate environmental behavior. UC Berkeley: Institute of Governmental Studies. 262-288

Toffler, B. (2003). Final Accounting. New York, New York, Random House Inc., pg.44-49

Toffler, B. Phone Interview. 31 July 2013

Tragger, et. al. (2001) The Effectiveness of Psychological Profiles. Journal of Police and Criminal Psychology.16.1, 20-28. $<$ http://download.springer.com/static/pdf/746/art\%3 A 1 10.1007\%2FBF02802730.pdf?auth66=1384300424_7a1503adbf1ef67cad75bad1ce6ecfae\&ext $=. p d f>$

Two decades of CEO pay. (2012). Forbes. $<$ http://www.forbes.com/lists/2012 /12/ceo-compensation-12-historical-paychart.html>

Vazsonyi, A. T., et al. (2001). An Empirical Test Of A General Theory Of Crime: A Four-Nation Comparative Study Of SelfControl And The Prediction Of Deviance. Journal Of Research In Crime \& Delinquency, 38.2, 91-131 Watkins, S. Email Interview. 11 Aug 2013.

Zahra, S. A.et. al. (2005). The Antecedents And Consequences Of Top Management Fraud. Journal Of Management, 31.6, 813 


\section{NOTES}

